\title{
Improving outcomes for homeless people with alcohol disorders: A multi-program community-based approach
}

\author{
Gary A. Morse ${ }^{1 *}$, Mary M. York ${ }^{2}$ and Julie Blanco \\ ${ }^{1}$ Places for People: Community Alternatives for Hope, Health, and Recovery, 4130 Lindell Blvd., St. Louis, MO 63108, USA \\ ${ }^{2} \mathrm{LMSW}$, Southern Illinois Healthcare, USA
}

\begin{abstract}
Background: Relatively few community-based programs have been found to be helpful for homeless people with alcohol disorders, even though this group represents a high-risk and vulnerable population prone to poor outcomes. Aims: The current study sought to implement and evaluate intensive community-based programs for homeless people with alcohol disorders.

Method: the project worked closely with a homeless outreach team for referrals, and then provided two different, intensive substance abuse treatment approaches matched to the needs of two subgroups: homeless individuals with alcohol disorders without severe mental illness received Community Reinforcement Approach (CRA) and case management services, while those with alcohol and severe mental illness were assigned to Assertive Community Treatment and Integrated Dual Disorders (ACT/IDDT) services. The study enrolled 321 homeless people with alcohol disorders and outcomes were assessed at six months and program discharge. Results: Participants improved significantly over the first six months in a number of outcome areas, including substance abuse, mental health, housing, employment, and health; progress generally remained stable between six months and discharge.
\end{abstract}

Conclusion: Community-based programs that coordinate with mobile outreach teams and then provide CRA and ACT/IDDT appear to be promising approaches for helping individuals with alcohol disorders out of homelessness and into recovery.

\section{Improving outcomes for homeless people with alcohol disorders: A multi-program community-based approach}

Homelessness continues to be a major problem in Great Britain, the United States, and other Western nations, with estimates of 380,000 people in Great Britain and 740,000 homeless in the United States at any one point in time, with well over one million people homeless annually in both countries [1]. People who are homeless face multiple health problems, with alcohol disorders being the most prevalent mental health disorder: rates of alcohol disorders range up to $58.5 \%$, which far exceeds the prevalence rate for non-homeless individuals [1]. Individuals with alcohol disorders represent an especially highneed and vulnerable subpopulation of people who are homeless [2]. Homeless people with alcohol disorders experience an especially high rate of co-morbid problems, including chronic homelessness, mental health disorders, trauma, poor life satisfaction, unemployment, criminal problems, a plethora of health problems, and early mortality [1-5]. Although there is a tendency in public discussions to think of homeless alcoholics as a single group, empirical research suggests there are at least two distinct, large subgroups: those with primary alcohol disorders without severe mental illness, and those with alcohol disorders and co-occurring severe mental illness [6].

Despite the high prevalence and seriousness of the problems associated with alcohol abuse among homeless people, there are relatively few treatment programs for this vulnerable population: one study found that only $6 \%$ of homeless people were currently receiving substance abuse treatment despite a prevalence rate of $57 \%[5,7]$. The United States government stated that homeless people with substance abuse disorders "face enormous competition for limited treatment slots" [8] even while noting that many homeless individuals "are not ready for abstinence-oriented programs" (p. 64). Although most homeless individuals with alcohol disorders are not currently receiving substance abuse treatment, they frequently utilize other costly resources, including emergency rooms, hospitals, community medical and social services in addition to shelters [5,9]. Research on effective treatment approaches for homeless people with alcohol disorders is also sparse in comparison to the scale and seriousness of the problem, but limited research does suggest some promising service possibilities, beginning with homeless outreach and engagement [5,10-13], and including motivational approaches [5], the community-reinforcement approach [14] and, for those with co-occurring severe mental illness, assertive community treatment with integrated dual disorder treatment $[9,15]$.

The primary objective of the current study was to implement and evaluate a comprehensive community-based program for homeless people with alcohol disorders. Specifically, the project implemented a staged approached, beginning with homeless outreach and motivational approaches, and then followed by two different, intensive substance abuse treatment approaches matched to the needs of two subgroups: homeless individuals with alcohol disorders but without severe mental illness received CRA services, while those with alcohol and severe mental illness were assigned to ACT/IDDT services. It was

Correspondence to: Gary A. Morse, Places for People: Community Alternatives for Hope, Health, and Recovery, 4130 Lindell Blvd., St. Louis, MO 63108, USA Tel: 314-535-5600 x426; Fax: 314-535-4634; E-mail: gmorse@placesforpeople.org

Received: April 20, 2016; Accepted: April 27, 2016; Published: April 30, 2016 
hypothesized that individuals referred to the intensive programs (CRA or ACT/IDDT) would improve over time in terms of substance abuse, mental health, housing, and other social outcomes.

\section{Method}

\section{Sample eligibility/recruitment/informed consent}

Recruitment began in December, 2008 and continued to June, 2013 in St. Louis, Missouri. Individuals were eligible to participate in the program if they signed an informed consent form (approved by agency Institutional Review Board) and met two inclusion criteria. These were that the individuals a) met the criteria for homelessness or at risk of homelessness; and b) met the criteria for a substance abuse disorder. Participants were recruited from a community-based mental health homeless outreach team, which identified and engaged potential participants at community sites including homeless shelters, drop-in centers, hospital emergency departments, drug courts and the streets. Once a comprehensive screening [which included the Simple Screening Instrument for Substance Abuse [16] and the Mental Health Screening Form III [17] and treatment assessment had been completed, and it was determined that individuals met the study inclusion criteria, they were linked with the most clinically-appropriate treatment team and consented to be in the research study. Participants were paid $\$ 10$ for each data collection interview.

\section{Participants}

Overall, participants $(\mathrm{N}=321)$ were primarily male $(61 \%)$ and African American (69\%). Thirty-eight percent were between the ages of 45 and 54 years of age, and $44 \%$ reported having attained less than a high school education. Separated by subgroup, the majority of our sample participated in CRA services (83\%), while the remaining 17\% participated in ACT/IDDT services.

\section{CRA \& ACT/IDDT interventions}

As noted, all project participants initially received initial homeless outreach and engagement services [12] from a mobile mental health team that helped to engage participants into services while providing initial case management assistance and motivational interviewing [18], and then were admitted to the outcome study and assigned to one of two treatment types, based on whether or not the individual had a cooccurring severe mental illness. Participants without severe mental illness (schizophrenia spectrum or bipolar disorders) were linked to a CRA program provided at a community behavioral health care organization. Providers were trained in CRA for homeless people [14] by one of the model developers, and received monthly consultation calls and fidelity monitoring by a national CRA technical assistance center. Local provider staff provided CRA interventions to participants in both individual and group modalities, while also providing a limited amount of case management assistance (e.g., to locate housing). Participants with co-occurring severe mental illness were linked to an ACT/IDDT program at the same community-agency; providers were trained and experienced in the ACT/IDDT model $[9,15]$ and participants received a range of treatment, rehabilitation and support services from this program, based on individual treatment plans.

\section{Design, data collection and measures}

Program outcomes were assessed by employing a quasiexperimental, pre-post design with a single cohort of 323 participants, with outcome data collected by trained research associates during individual interviews at baseline, at six-months (with a $80.7 \%$ followup rate), and at program discharge ( 235 clients were discharged by the end of the study period with a mean time in the project of 7.27 months, standard deviation of 3.15 days, while the other participants remained in services). Baseline and outcome data were collected primarily on a battery of measures that were selected based on the weight of the empirical evidence supporting their use as well as their clinical appeal for this population. The battery included three main outcome measures of substance abuse: the Alcohol Use Scale (AUS), the Drug Use Scale (DUS), and the Substance Abuse Treatment Scale (SATS). The study also employed three measures of mental health symptoms: Colorado Symptom Index (CSI), the Quick Inventory of Depression SymptomSelf-Report (QIDS-SR), and a newly developed Anxiety Scale. [4] reported good inter-rater reliability for the AUS, DUS, and SATS, (i.e., coefficients typically exceed .80). The CSI has been widely used, is easy to understand and administer, has been found to be reliable across gender and ethnic groups, and are appropriate for individuals of all educational levels and especially appropriate for assessing more severe symptoms Conrad et al., 2001; Kroenke, Spitzer, \& Williams, 2001 and the QIDS-SR has been found to have excellent validity and reliability [19]. The Anxiety Scale reflects DSM-IV criteria and shows face validity, and has been used in similar research studies.

In addition to the substance abuse and mental health measures, we collected data on several other variables salient for this population. In particular, we collected housing status (stably housed, homeless, etc.) data using an interview question that has been employed in prior outcome research with homeless people $[9,15]$. We also used the CSAT Government Performance and Results Act (GPRA) measure to collect self-report data on employment, general health, and crimes committed in the past 30 days.

\section{Data analysis}

Data analyses were conducted using SPSS software. Descriptive statistics (e.g., means and standard deviations) as well as comparisons of baseline to follow-up data outcome variables were tested for statistical significance for the entire sample using the paired t-test. Data were analyzed for the entire sample over time.

\section{$\underline{\text { Results }}$}

As shown in Table 1, there were significant improvements in substance abuse for the entire sample from baseline to six months and these gains held stable from six months to discharge. Specifically, alcohol use as measured on the AUS declined significantly from baseline to six months, $t=6.08$ (244), $p<.001$, and remained unchanged from six months to discharge, $t=1.15(151), p=.25$. Similarly, drug use on the DUS declined significantly from baseline to six months, $t=8.57(244)$, $p<.001$ and remained stable from six months to discharge $t=.65(151)$, $p=.52$. The SATS also showed a significant improvement from baseline to six months, $t=10.63(244) p<.001)$, with no significant changes from six months to discharge $t=1.02(151) p=.31$.

Mental health symptoms were significantly lower at six months than at baseline on the QIDS, $t=2.68(168), p=.01$, CSI, $t=8.03(235)$, $p<.001$, and anxiety scale, $t=5.75(189), p<.001$. Symptom scores did not change significantly between six months and discharge on the QIDS, $t=1.50$ (134), $p=.14$, or CSI, $t=1.22(154), p=.15$, but anxiety was slightly lower at discharge than at six months, $t=2.35(132), p=.02$. 
Housing outcomes improved during the treatment program. The number of nights spent in stable housing conditions improved significantly from baseline to six months and this improvement in stable housing from baseline did not change significantly from six months to discharge (Table 1). The number of nights spent on the street or in shelters also decreased significantly from baseline to six months, and then decreased significantly again from six months to discharge (Table 1). Nights spent in precariously housed situations (e.g., hotels, friend's house) and nights spent in institutions (e.g., jail or hospitals) did not change significantly throughout the study period.

Other social outcomes also improved from baseline to six months (Table 2). There was improvement in the number of people employed full- or part-time, with a lower proportion of people who were unemployed and looking for work $\left(\mathrm{X}^{2}=41.72, p<.001\right)$. Data indicate that at the six month follow-up, people reported committing fewer crimes $\left(\mathrm{X}^{2}=74.13, p<.001\right)$ and having better overall health $\left(\mathrm{X}^{2}=13.49\right.$, $p<.01)$. Fewer people reported being in "poor health" than would have been expected based on baseline levels; similarly, more people reported being in "excellent" and "good" health than would have been expected based on baseline levels. There were no significant differences on the employment and health variables between six months and discharge, but the number of crimes committed again dropped significantly during this study period, $\mathrm{x}^{2}=9.68, p=.02$.

\section{Discussion}

The results strongly support the study hypothesis that the intensive interventions, matched to the mental health needs of the clients, were associated with robust outcomes over time for people who are homeless with alcohol disorders. The breadth of positive changes for participants was impressive, involving multiple outcome domains, including substance abuse (alcohol, drugs, and stage of change), mental health (depression, anxiety, and more severe symptoms), housing (decreasing homelessness and increasing stable housing), employment, criminal behavior, and physical health. Results indicated that positive change occurred within the first six months of service provision and that changes then generally remained stable between

Table 1. Summary of substance abuse, mental health, and housing outcome measures.

\begin{tabular}{|l|c|c|c|}
\hline & \multicolumn{3}{|c|}{ Overall } \\
\hline & \multicolumn{3}{|c|}{ Mean, $\mathrm{t}-$ value $(\mathrm{n})$} \\
\hline AUS & Baseline**** & 6 Month F/U & Discharge \\
\hline DUS & 3.37 & $2.80, \mathrm{t}=6.08(243)^{*}$ & $2.78, \mathrm{t}=1.15(150)$ \\
\hline SATS & 3.15 & $2.35, \mathrm{t}=8.57(243)^{*}$ & $2.26, \mathrm{t}=0.65(150)$ \\
\hline QIDS & 2.98 & $4.28, \mathrm{t}=10.63(243)^{*}$ & $1.02, \mathrm{t}=0.31(150)$ \\
\hline CSI & 13.78 & $12.19, \mathrm{t}=2.68(188)^{* *}$ & $11.31, \mathrm{t}=1.50(133)$ \\
\hline Anxiety & 31.40 & $24.79, \mathrm{t}=8.03(234)^{*}$ & $24.23, \mathrm{t}=1.44(153)$ \\
\hline Stable Housing Days & 20.57 & $16.00, \mathrm{t}=5.75(188)^{*}$ & $15.67, \mathrm{t}=2.35(131)^{* * *}$ \\
\hline Homeless Days & 1.68 & $8.02, \mathrm{t}=7.27(224)^{*}$ & $7.19, \mathrm{t}=0.76(151)$ \\
\hline
\end{tabular}

${ }^{*} \mathrm{p}<0.001, * * \mathrm{p}<0.01, * * * \mathrm{p}<0.05$

****Means shown represent baseline to 6-month sample. Means may vary slightly for the 6-month to discharge sample due to varying sample size.

Table 2. Summary of social and general health measures.

\begin{tabular}{|l|c|c|}
\hline \multicolumn{1}{|c|}{ Baseline } & 6 Month F/U \\
\hline Currently Employed & $(18) 5.60 \%$ & (33) $12.7 \%, \chi^{2}=39.80^{*}$ \\
\hline Committed Crime in Past 30 days & $(200) 62.11 \%$ & (97) $37.02 \%, \chi^{2}=74.12^{*}$ \\
\hline Poor Physical Health & (81) $25.23 \%$ & (45) $17.18 \%, \chi^{2}=16.69^{* *}$ \\
\hline
\end{tabular}

$* * \mathrm{p}<0.01$ six months and discharge from services. The results are generally consistent with (though even more robust than) other studies finding positive outcomes for homeless people with alcohol disorders when served by CRA [14] or by ACT/IDDT for those with co-occurring severe mental illness, $[9,15]$, and further supports the effectiveness of a comprehensive approach to serving homeless people with alcohol disorders through outreach, motivational interviewing, CRA and ACT/IDDT services [20]. Confidence in these findings is tempered by methodological limitations of the study, especially the absence of an experimental design involving a randomized control or comparison group. Future research should seek to replicate the effectiveness of this approach to serving homeless people through outreach, CRA and ACT/IDDT services using a randomized design and control group with a longer follow-up interval.

People who are homeless with alcohol disorders are an especially high-need, vulnerable population. Perhaps because of the stigma associated with "homeless alcoholic," it is also a group that seems to have been somewhat neglected in health policy, as evidenced by the shortage of both service programs and outcomes research, as compared to the scope and seriousness of the problem. Despite some research limitations, the present study provides hopeful results that communities can effectively help the sizeable population of homeless people with alcohol disorders out of homelessness and toward substance abuse recovery, while also improving mental health, health, and social outcomes such as employment and criminal activity.

\section{Acknowledgement}

The project was supported in part SAMHSA grant TI020617. The authors would also like to acknowledge the contributions of a number of individuals with this study, including Ellen Levine, Barbara Zawier, Tracie Mulderig, and Bonnie Barbareck. The authors report no conflicts of interest.

\section{References}

1. Fazel S, Khosla V, Doll H, Geddes J (2008) The prevalence of mental disorders among the homeless in western countries: systematic review and meta-regression analysis. PLoS Med 5: e225. [Crossref]

2. Baumohl J, Huebner R (1991) Alcohol and other drug problems among the homeless: research, practice and future directions. Housing Policy Debate 2: 837-866.

3. Calsyn RJ, Morse GA (1991) Correlates of problem drinking among homeless men Hosp Community Psychiatry 42: 721-725. [Crossref]

4. Drake RE, Essock SM, Shaner A, Carey KB, Minkoff K, et al. (2001) Implementing dual diagnosis services for clients with severe mental illness. Psychiatr Serv 52: 469476. [Crossref]

5. Wright NM, Tompkins CN (2006) How can health services effectively meet the health needs of homeless people? Br J Gen Pract 56: 286-293. [Crossref]

6. Morse GA, Calsyn RJ, Burger G (1992) Development and cross-validation of a system for classifying homeless people. Journal of Community Psychology 20: 228-242.

7. Morse GA, Calsyn RJ (1986) The St. Louis mentally disturbed homeless: needy, willing, but under served. International Journal of Mental Health 1: 74-94.

8. SAMHSA (2003) Blueprint for change: ending chronic homelessness for persons with serious mental illnesses and/or co-occurring substance use disorders. Rockville: Department of Health and Human Services.

9. Morse GA, Calsyn RJ, Klinkenberg WD, Helminiak TW, Wolff N, et al. (2006) Treating homeless clients with severe mental illness and substance use disorders: costs and outcomes. Community Mental Health Journal 377-404.

10. Bybee D, Mowbray CT, Cohen E (1995) Evaluation of a homeless mentally ill outreach program: differential short-term effects. Evaluation and Program Planning 18: 13-24.

11. Lam JA, Rosenheck R (1999) Street outreach for homeless persons with serious mental illness: is it effective? Med Care 37: 894-907. [Crossref] 
12. Morse GA, Calsyn RJ, J Miller, Rosenberg P, West L, et al. (1996) Outreach to homeless mentally ill people: Conceptual and clinical considerations. Community Mental Health Journal 261-274.

13. Tommasello AC, Myers CP, Gillis L, Treherne LL, Plumhoff M, et al. (1999) Effectiveness of outreach to homeless substance abusers. Eval Program Plann 22: 295303. [Crossref]

14. Smith JE, Myers RJ, Delaney HD (1998) The community reinforcement approach with homeless alcohol-dependent individuals. Journal of Consulting and Clinical Psychology 66: 541-548.

15. Morse GA, Calsyn RJ, Klinkenberg WD, Cunningham J, Lemming MR, et al. (2008) Integrated treatment for homeless clients with dual disorders: A quasi-experimental evaluation. Journal of Dual Diagnosis 3: 319-336.
16. Boothroyd RA, Peters RH, Armstrong MI, Rynearson-Moody S, Caudy M2 (2015) The Psychometric Properties of the Simple Screening Instrument for Substance Abuse. Eval Health Prof 38: 538-562. [Crossref]

17. Carroll JFX, McGinley JJ (2001) Mental Health Screening Form-III (MHSF-III). New York, NY: Project Return.

18. Miller WR, Rollnick S (2012) Motivational interviewing: Helping people change. Guilford press.

19. Rush A, Trivedi M, Ibrahim H, Carmody T, Arnow B, et al. (2003) The 16 item quick inventory of depressive symptomalogy (QIDS), clinician rating (QIDS-C) and selfreport (QIDS-SR). Biological Psychiatric Journal 573-583.

20. Scott J (1993) Homelessness and mental illness. Br J Psychiatry 162: 314-324. [Crossref]

Copyright: (C2016 Morse GA. This is an open-access article distributed under the terms of the Creative Commons Attribution License, which permits unrestricted use, distribution, and reproduction in any medium, provided the original author and source are credited. 